\title{
Lung volume reduction surgery: what can we learn from the National Emphysema Treatment Trial?
}

\author{
E.W. Russi, K.E. Bloch, W. Weder
}

Lung volume reduction surgery (LVRS), originally proposed $>4$ decades ago by BRANTIGAN et al. [1], was reintroduced by COOPER et al. [2]. This pioneer work provided tremendous incentives not only for other research groups worldwide to corroborate the efficacy of LVRS, as well as to uncover criteria for patient selection and predictors of outcome, but was also a unique opportunity to comprehensively study the physiology of end-stage emphysema.

Clinicians with the opportunity to observe the remarkable improvements in shortness of breath and lung function after surgery in appropriately selected patients did not need not to be persuaded that such changes are real and cannot be attributed to a placebo effect. Several large case series from centres with considerable experience have demonstrated a low operative mortality $(<5 \%)$ and significant improvements in symptoms, pulmonary function, and exercise capacity in the short and intermediate term after LVRS [3-7]. Three prospective randomised studies confirmed functional improvements in the operated group, whereas this was not observed in the conservativelytreated control arm [8-10]. Nonetheless, controversy remained with respect to potential benefits and risk of the procedure $[11,12]$. This prompted the editor of a prestigious journal to claim that only adequately controlled clinical trials would prove that LVRS eventually works [13, 14].

Initial enthusiasm for LVRS was soon dampened due to reports on surgical mortality rates of up to $17 \%$ [9]. A review of Medicare claims showed a 6-month mortality rate of $16.9 \%$ [15]. Since many surgeons started to perform LVRS in desperate chronic obstructive pulmonary disease (COPD) patients without including them at least in prospective case series to ascertain a certain quality control, it was understandable that some health insurance companies stopped paying for LVRS in the USA. Eventually, the National Heart, Lung, and Blood Institute and the Center for Medicare and Medicaid Services (formerly the Health Care Financing Administration) came to sponsor a multicentre, randomised clinical trial, the National Emphysema Treatment Trial (NETT).

At 17 clinics, a total of 1,218 patients with severe emphysema underwent pulmonary rehabilitation and were subsequently randomly assigned to undergo LVRS or to receive continued medical treatment. Eight centres performed LVRS by median sternotomy alone, three centres by video-assisted thoracic surgery alone, and six by median sternotomy or video-assisted thoracic surgery. Patients underwent reevaluations at 6 months, 12 months, and yearly thereafter. The primary outcome measures were overall mortality and

Pulmonary Division and Division of Thoracic Surgery, University Hospital, Zurich, Switzerland.

Correspondence: E.W. Russi, Pulmonary Division, University Hospital, Raemistr. 100, CH-8091, Zürich, Switzerland. Fax: 4112554451. E-mail: erich.russi@usz.ch changes in maximal exercise capacity measured on a cycle ergometer. Secondary outcome measures included pulmonary function, the distance walked in $6 \mathrm{~min}$, and the results of questionnaires about health-related quality of life, and dyspnoea.

At the outset of the study, the investigators provided the data and safety monitoring board with stopping guidelines, which were to be used to identify subgroups that benefited from lung-volume reduction surgery, as well as subgroups whose risk was unacceptably increased by the procedure. Both the investigators and the data and safety monitoring board considered a 30-day surgical mortality $>8 \%$ to be unacceptable. In April 2001, these analyses suggested that certain patients had increased 30-day mortality. This resulted in an early press release of a widely noted article in the New England Journal of Medicine [16]. For 69 patients who had a forced expiratory volume in one second (FEV1) that was $\leqslant 20 \%$ predicted and either a homogeneous distribution of emphysema on a computed tomography scan or a carbon monoxide diffusing capacity $\leqslant 20 \%$ pred, the 30 -day mortality rate after surgery was $16 \%$, as compared with a rate of $0 \%$ among 70 matched medically-treated patients $(\mathrm{p}<0.001)$. Survivors of surgery in this subgroup experienced only minor improvements at 6 months in the maximal exercise capacity $(p=0.06)$, the distance walked in $6 \mathrm{~min}(\mathrm{p}=0.03)$, and in FEV1 $(\mathrm{p}<0.001)$, but a similar health-related quality of life compared with the medically treated patients. Based on these results, patients with the cited characteristics were no longer recruited for the trial and are thought to be poor candidates for LVRS.

Recently, the eagerly awaited results of the completed NETT have been published [17]. The results reveal no difference in overall mortality among 680 patients assigned to the surgical arm versus 610 patients assigned to the medical treatment arm (1.1 deaths per person per year) after a mean observation period of 29.2 months of follow-up. After 2 yrs, mean values for maximal exercise capacity, FEV1, and quality of wellbeing were higher in the surgical compared with the medical group, and exercise capacity had improved by $>10 \mathrm{~W}$ in $15 \%$ of patients in the surgery group, as compared with $3 \%$ of patients in the medical-therapy group $(\mathrm{p}<0.001)$. Therefore, this large randomised trial corroborates the effectiveness of LVRS in selected patients. One important purpose of the NETT was to identify subgroups of patients that might benefit or be at increased risk from LVRS. The authors list 16 patient characteristics that they considered in defining such subgroups. In a post hoc analysis they found that among patients with predominantly upper-lobe emphysema and low exercise capacity, mortality was lower in the surgery group than in the medical-therapy group (risk ratio for death, 0.47; $\mathrm{p}=0.005$ ). On the other hand, among patients with nonupperlobe emphysema and high exercise capacity, mortality was higher in the surgery group than in the medical-therapy group (risk ratio 2.06; $\mathrm{p}=0.02$ ). A maximal workload of 25 watts for 
females and 40 watts for males was used to discriminate between low and high exercise capacity, since these sexspecific cut-off points were found to correlate best with the differential risk of death from LVRS. A further subgroup analysis revealed that patients with upper-lobe emphysema and high baseline exercise capacity showed no survival benefit from LVRS but an improved exercise capacity, whereas patients with nonupper-lobe emphysema and high exercise capacity had no statistically significant difference in survival or exercise capacity after LVRS as compared with the medical treatment.

\section{Answers from the National Emphysema Treatment Trial}

\section{What are the major effects of lung volume reduction surgery?}

This extensive trial confirms the findings of three randomised trials and several previously published uncontrolled series; carefully selected patients with severe emphysema who remain considerably limited by shortness of breath despite optimal medical therapy, including comprehensive pulmonary rehabilitation, benefit from LVRS with respect to relief of breathlessness, quality of life, pulmonary function and exercise capacity. LVRS can be performed with a relatively low perioperative mortality of $5 \%$.

\section{Which patients are at high risk of perioperative mortality?}

LVRS is afflicted by a high perioperative mortality in patients where lung function, particularly gas exchange, is severely impaired as estimated by an FEV $1 \leqslant 20 \%$ pred and single-breath diffusing capacity $\leqslant 20 \%$ pred, due to an almost entirely destroyed lung ("vanished lung") as assessed in the chest computer tomography scan. Such patients have been excluded from LVRS from the beginning by most experienced centres worldwide, based on sound physiological considerations resulting in a perioperative mortality rates of $<5 \%$ [18].

\section{Does lung volume reduction surgery prolong life?}

The survival of properly selected patients is not shortened by LVRS, and may even be improved in some patients. The presented data provide valuable information on the natural history and survival of a conservatively treated and wellcharacterised population of patients with severe COPD after 2 yrs. It will be interesting to get survival data after an observation time of $5 \mathrm{yrs}$.

Can the response to lung volume reduction surgery from emphysema morphology be predicted?

NETT confirms the findings that patients with a heterogeneous upper-lobe type of emphysema experience a larger functional improvement than patients with other types of emphysema morphology [7]. The trial does not exclude, however, that patients with homogeneously distributed emphysema may also benefit from LVRS.

\section{Open questions}

Surgical results are dependent from the case load, i.e. the experience of a team. Particularly, experience may play an important role in cases with a homogeneous type of emphysema, where the location and the amount of resectable tissue is less well defined than in patients with heterogeneous emphysema. Altogether, 608 patients were operated on at 17 centres, which gives an average of 36 interventions performed at each centre over a period of several years, most likely by several surgeons. This number is considerably lower than that reported by teams with larger case series $[3,7,19]$.

NETT reports only changes in FEV1, maximal workload and quality of well-being, and data are presented as histograms of changes from baseline [17]. Various interesting functional aspects, such as the degree of hyperinflation and parameters of gas-exchange, are not reported in the NETT paper or its addendum. Therefore, it is difficult to make more detailed analysis and comparisons with published data. However, despite this limitation, it seems that the achieved improvement in FEV1 is clearly less than reported in the literature [3]. The current authors have analysed their results with respect to changes in FEV1 3-6 months after surgery and present the data in a similar manner as the NETT trialists (fig. 1). In the authors' study population the proportion of patients with postoperative changes in FEV1 $>10 \%$ pred was higher and the mortality was lower as compared with NETT and in accordance to the findings of COOPER et al. [2]. This may relate to differences in patient selection, surgical expertise, and various other factors.

The classification into predominantly upper-lobe and nonupper-lobe emphysema is a crude simplification, which does not reflect the range of emphysema morphology encountered in daily practice. A more detailed categorisation to test the role of emphysema morphology on the outcome of LVRS would have extended previous knowledge on the role of this classification [20].

Patients with alpha-1 antitrypsin (A1ATD) deficiency are an important category in subjects suffering from advanced pulmonary emphysema. Few uncontrolled studies report on the outcome of this subset of patients who characteristically have predominantly, but not exclusively, heterogeneous lowerlobe emphysema [21, 22]. In A1ATD the functional gains after surgery are comparable at 6 months but are shorter lasting in the majority than in pure smokers' emphysema. However, a large and unexplained variability of the effects of LVRS is found among patients [23]. In the NETT A1ATD was not declared as an exclusion criterion. The current authors

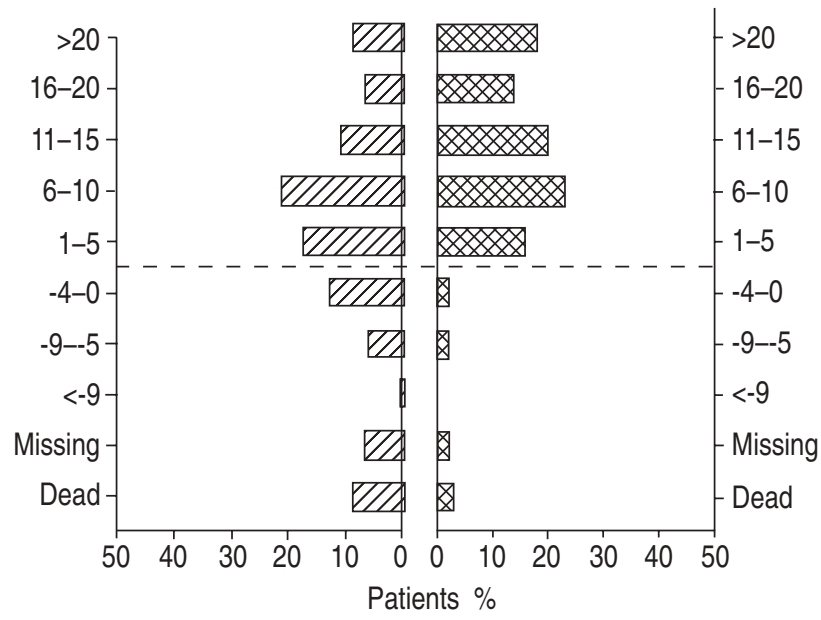

Fig. 1.-Changes in forced expiratory volume in one second 6 months after lung volume reduction surgery (LVRS) in the National Emphysema Treatment Trial $(65 \%>0,35 \%<0, \mathrm{p}<0.001, \mathrm{n}=508$, modified from [16]) $(\mathbb{Z})$, and within 3-6 months of LVRS at the University Hospital of Zurich $(90 \%>0,10 \%<0, n=173)$ (D). 
expected that supplementary analyses would be reported that shed some light on this controversial issue.

Pulmonary rehabilitation lasting 6-10 weeks was a prerequisite to be a candidate for randomisation in the NETT. No information is provided on how much this outpatient procedure changed exercise capacity and health-related quality of life.

Low exercise capacity was suggested to be a predictor of favourable outcome in patients with upper-lobe, as well as with nonupper-lobe emphysema based on a post hoc analysis. This needs to be confirmed in prospective investigations [24]. Furthermore, exercise capacity was assessed by cycle ergometry with the patient breathing $30 \%$ oxygen. This is unusual in most pulmonary function laboratories.

Issues of cost-effectiveness are complex, particularly for procedures such as LVRS, where the main goal is palliation and not prolongation of life. The findings of NETT, that LVRS is costly relative to medical therapy, are unsurprising [25]. As expected, the cost-effectiveness ratio for LVRS as compared with medical treatment was greatest for the group in which LVRS gave the best improvement and had even a positive impact on survival, i.e. for patients with predominantly upper-lobe emphysema and low exercise capacity. However, cost calculations will vary considerably with each health system and the reported finding probably does not apply to most of the European centres.

\section{References}

1. Brantigan OC, Mueller EA, Kress MB. A surgical approach to pulmonary emphysema. Am Surg 1957; 23: 789-804.

2. Cooper JD, Trulock EP, Triantafillou AN, et al. Bilateral pneumectomy (volume reduction) for chronic obstructive pulmonary disease. J Thorac Cardiovasc Surg 1995; 109: 106-109.

3. Ciccone AM, Meyers BF, Guthrie TJ, et al. Long-term outcome of bilateral lung volume reduction in 250 consecutive patients with emphysema. I Thorac Cardiovasc Surg 2003; 125: 513-525.

4. Gelb AF, McKenna RJ. Lung volume reduction surgery update. Chest 2003; 123: 975-977.

5. Wisser W, Tschernko E, Senbaklavaci O, Kontrus M, Wanke T, Klepetko W. Functional improvements after volume reduction: sternotomy versus videoendoscopic approach. Ann Thorac Surg 1997; 63: 822-828.

6. Hamacher J, Bloch KE, Stammberger U, et al. Two years' outcome of lung volume reduction surgery in different morphologic emphysema types. Ann Thorac Surg 1999; 68: 1792-1798.

7. Bloch KE, Georgescu CL, Russi EW, Weder W. Gain and subsequent loss of lung function after lung volume reduction surgery in cases of severe emphysema with different morphologic patterns. J Thorac Cardiovasc Surg 2002; 123: 845854.

8. Criner GJ, Cordova FC, Furukawa S, et al. Prospective randomized trial comparing bilateral lung volume reduction surgery to pulmonary rehabilitation in severe chronic obstructive pulmonary disease. Am J Respir Crit Care Med 1999; 160: 2018-2027.

9. Geddes D, Davies M, Koyama H, et al. Effect of lungvolume-reduction surgery in patients with severe emphysema. $N$ Engl J Med 2000; 343: 239-245.

10. Pompeo E, Marino M, Nofroni I, Matteucci G, Mineo TC. Reduction pneumoplasty versus respiratory rehabilitation in severe emphysema: a randomized study. Pulmonary Emphysema Research Group. Ann Thorac Surg 2000; 70: 948-953.

11. Cooper JD, Lefrak SS. Is volume reduction surgery appropriate in the treatment of emphysema? Yes. Am J Respir Crit Care Med 1996; 153: 1201-1204.

12. Make BJ, Fein AM. Is volume reduction surgery appropriate in the treatment of emphysema? No. Am J Respir Crit Care Med 1996; 153: 1205-1207.

13. Drazen JM. Surgery for emphysema - not for everyone. $N$ Engl J Med 2001; 345: 1126-1128.

14. Drazen JM, Epstein AM. Guidance concerning surgery for emphysema. N Engl J Med 2003; 348: 2134-2136.

15. Heath Care Financing Administration. Report to congress. Lung volume reduction surgery and Medicare coverage policy: implications of recently published evidence. Baltimore, Heath Care Financing Administration, 1998.

16. National Emphysema Treatment Trial Research Group. Patients at high risk of death after lung-volume-reduction surgery. N Engl J Med 2001; 345: 1075-1083.

17. Fishman A, Martinez F, Nauheim K. A randomized trial comparing lung-volume-reduction surgery with medical therapy for severe emphysema. $N$ Engl J Med 2003; 348: 2059-2073.

18. Russi EW, Stammberger U, Weder W. Lung volume reduction surgery for emphysema. Eur Respir J 1997; 10: 208-218.

19. Gelb AF, McKenna RJ, Brenner M, Epstein JD, Zamel N. Lung function 5 yrs after lung volume reduction surgery for emphysema. Am J Respir Crit Care Med 2001; 163: 15621566.

20. Thurnheer R, Engel H, Weder W, et al. Role of lung perfusion scintigraphy in relation to chest $\mathrm{CT}$ and pulmonary function in the evaluation of candidates for lung volume reduction surgery. Am J Respir Crit Care Med 1999; 159: 301-310.

21. Gelb AF, McKenna RJ, Brenner M, Fischel R, Zamel N. Lung function after bilateral lower lobe lung volume reduction surgery for alphal-antitrypsin emphysema. Eur Respir J 1999; 14: 928-933.

22. Cassina PC, Teschler $\mathrm{H}$, Konietzko $\mathrm{N}$, Theegarten $\mathrm{D}$, Stamatis G. Two-year results after lung volume reduction surgery in alphal-antitrypsin deficiency versus smoker's emphysema. Eur Respir J 1998; 12: 1028-1032.

23. Tutic M, Bloch K, Lardinois D, Brack T, Russi EW, Weder $\mathrm{W}$. Long term result after long volume reduction surgery in patienst with alpha-1 anitrypsin deficiency. $J$ Thorac Cardiovasc Surg 2003; (In press).

24. Ware JH. The national emphysema treatment trial - how strong is the evidence? $N$ Engl J Med 2003; 348: 20552056.

25. Ramsey SD, Berry K, Etzioni R. Cost effectiveness of lungvolume-reduction surgery for patients with severe emphysema. N Engl J Med 2003; 348: 2092-2102. 